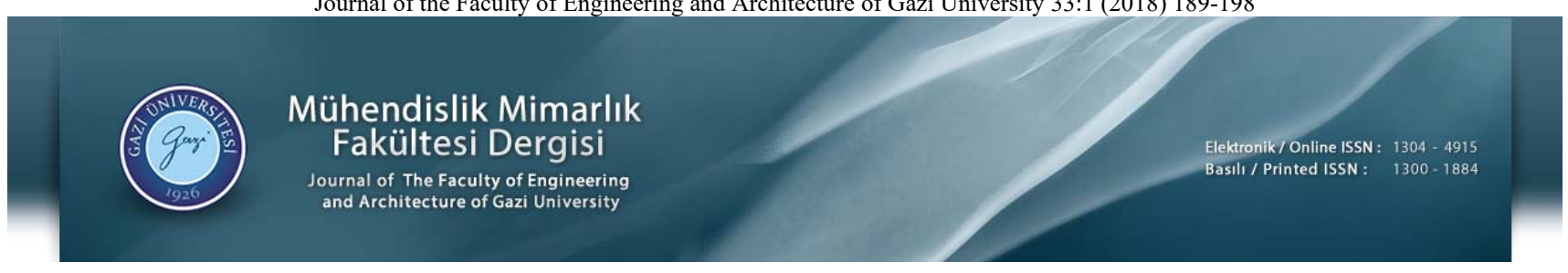

\title{
Hava nüveli, çok katmanlı, kademeli reaktörün optimum tasarım algoritması
}

\author{
Uğur Halil Arifoğlu*(ic) \\ $\underline{\text { Sakarya Üniversitesi, Mühendislik Fakültesi, Elektrik Elektronik Mühendisliği Bölümü, Kampüs, Serdivan, Adapazarı, 54187, Türkiye }}$
}

\section{Ö N E C I K A N L A R}

- En uygun çok katmanlı kademeli reaktör tasarımı

- Hava nüveli çok katmanlı reaktörün öz endüktans değer hesabı

- Hava nüveli kademeli reaktörün ortak endüktans değer hesabı

Makale Bilgileri

Geliş: 02.10.2016

Kabul: 01.07.2017

DOI:

10.17341/gazimmfd.406791

Anahtar Kelimeler:

Hava nüveli reaktör, çok katmanlı reaktör, kademeli reaktör, en uygun tasarım, ortak endüktans

\section{ÖZET}

Bu çalışmada, hava nüveli, çok katmanlı kademeli reaktörün optimum tasarımını yapan bir algoritma tanıtılmaktadır. Kademeli reaktörde kullanılan model, Kirchhoff gerilim yasasından hareketle, paralel bağlı her bir reaktör bobininin gerilim değerlerinin eşitliği prensibi üzerine bina edilmiştir. Kademeli reaktör iç çapının, belirlenen bir en küçük değer ile bir en büyük değer arasındaki ( $1 \mathrm{~cm}$ aralıkla artan) her farklı iç çap değeri için algoritma reaktörü tekrar tasarlar. Daha önce belirlenen en küçük ve en büyük değer arasındaki her bir iç çap değeri için, algoritma üç değer hesaplar; kademeli reaktörün aktif güç kaybı, kademeli reaktörün ağırlığı ve kademeli reaktörün yüksekliği. Hesaplanan bu üç farklı dizin (matrisin üç sütunu şeklinde) kaydedilir. Belirlenen tüm iç çap değerleri için hesaplama sona erdiğinde, matrisin her bir sütunu (düşey eksen) ve iç çap (yatay eksen) değerine bağlı olarak üç farklı eğri üretilmiş olur. İlk iki (reaktör aktif güç kaybı ve reaktör ağırlığı) eğrinin en küçük noktaları, aranılan en uygun (optimum) reaktör üretim değerlerini gösterir. Üretici iki farklı amaçtan hangisine göre üretim yapmayı düşünür ise ona ilişkin optimum değeri tercih eder. Kademeli reaktörün manyetik alan (öz ve ortak indüktans) hesaplamaları Lorenz, Maxwell eşitlikleri üzerine bina edilmiş ve 3. mertebeden eliptik entegraller kullanılmıştır.

\section{Optimum design of the air core multilayer tapped reactor}

\section{H I G H L I G H T S}

- Optimum design algorithm of air core multilayer tapped reactor

- The calculation of the self inductance of the air core tapped reactor

- The calculation of the mutual inductance of the air core tapped reactor

Article Info

Received: 02.10 .2016

Accepted: 01.07.2017

DOI:

$10.17341 /$ gazimmfd.406791

Keywords:

Air core reactor, multilayer reactor, tapped reactor, optimum design, mutual coupling

\section{ABSTRACT}

In this study, an algorithm which optimizes the multilayer tapped reactor has been introduced. The model used in the tapped reactor is based on the principle of equalization of the voltage values of each reactor coil connected in parallel with the Kirchhoff voltage law. The algorithm redesigns the reactor, inner diameter of the reactor for each different inner diameter value between a specified minimum value and a maximum value (increasing by $1 \mathrm{~cm}$ ). For each inner diameter value between the smallest and the largest value previously determined, the algorithm calculates three values; Active power loss of the tapped reactor, the weight of the tapped reactor, and the height of the tapped reactor. These three different indexes are calculated (in the form of three columns of the matrix). When the calculation ends for all the specified inner diameter values, three different curves are generated depending on each column (vertical axis) and inner diameter (horizontal axis) value of the matrix. The smallest points of the first two (reactor active power loss and reactor weight) curve show the optimum reactor production values sought. If the producer thinks to produce according to one of two different purposes, he chooses the optimum value for it. The magnetic field (self and common inductance) calculations of the tapped reactor are built on Lorenz, Maxwell equations and elliptic integrals of the third order are used. 


\section{GIRISŞ (INTRODUCTION)}

Hava nüveli çok katmanlı ve kademeli reaktörler akım sınırlama, gerilim ayarlama, reaktif güç kompanzasyonu ve filtreleme amacı ile iletim $[1,2]$ ve dağıtım sistemlerinde [3, 4] kullanılan cihazlardır. Ancak, bu reaktörlerin tasarımı zordur [5]. Reaktörün en önemli tasarım parametreleri; paket sayıs1, her bir paket içindeki bobin (layer) sayısı, her bir bobinin sarım sayısı, tel kesitleri, reaktör iç çapı, reaktör yüksekliği, reaktör ağırlığı, reaktör aktif güç kaybı olarak sayılabilir. Bu parametreler arasında ilişkiler de önemlidir. Örneğin, bobin sarım sayısı ile bobin yüksekliği arasında çok yakın bir ilişki söz konusudur. Tasarımda dikkate alınması gereken çok önemli bir diğer problem, eğer reaktör uygun bir şeklide tasarlanmaz ise, bobinler arasında ortaya çıkacak olan sirkülasyon akımlarının yaratacağı 1sınma sorunudur [6, 7]. Reaktör siparişi veren firma, reaktör üreticisine; reaktör öz indüktans değeri, reaktör akımı, reaktör gerilimi, çalışma frekansı, reaktörün boyu ya da enindeki (varsa) sınır değerleri, aktif güç kaybında izin verilen en büyük güç değeri, kısa devre akım değeri ve süresi, kabul edilebilir en büyük reaktör ağırlığg gibi taleplerini iletirler.

Tasarımcı ise, bu isterleri gözeterek, imal edilecek reaktörün tüm üretim parametrelerini hesaplamak zorundadır. Reaktörün, en hafif ya da en az enerji tüketen bir cihaz olması gerekir. Hava nüveli çok katmanlı kademeli reaktör tasarımını hedefleyen çeşitli yöntemleri literatürde görmek mümkündür. Isıl analiz yolu ile reaktör tasarımı [8], deri ve yakınlık etkisi altında reaktör tasarımı [9], sıcaklık ve alan dağılımı üzerine bina edilen reaktör tasarımı [10] bunlara örnek olarak verilebilir. Bu çalışmalarda amaç fonksiyonu olarak; bobin ve paket akımlarının eşitlenmesi, bobin teline ilişkin akım yoğunluklarının eşitlenmesi [11, 12], paket sicaklıklarının dengelenmesi $[13,14]$ ve bobinlerdeki gerilim düşümlerinin eşitlenmesini sağlayan eşitlikler kullanılmaktadır [15]. Özellikle [15]'de verilen yaklaşım, reaktör tasarımı için ne kadar çok miktarda parametreye ihtiyaç duyulduğunu ve bunların hesaplanmasındaki zorluğa işaret etmek bakımından örnek bir çalışma olarak verilebilir. $\mathrm{Bu}$ çalışmada, tasarımcısının tüm isterlerini sağlayan, aynı zamanda (tüketicinin tercihine bağlı olarak) en hafif veya en az güç kaybı ile çalışan kademeli bir reaktörün tüm üretim parametrelerini bulan bir algoritma önerilmektedir. $\mathrm{Bu}$ algoritma piyasadan gelen talep üzerine geliştirilmiş, yazılım kodları ile programa dönüştürülmüş, programın çalıştırılması sonunda bulunan tasarım parametrelerine göre reaktörün imalatı yapılmış ve tüketiciye ürünler teslim edilmiştir. Literatürde, yukarıda sayılan çıktıları sağlayarak reaktör imalatı hedefleyen içerikte bir algoritma bulunmamaktadır.

\section{HESAPLAMA YÖNTEMİ (CALCULATION METHOD)}

Hava nüveli çok katmanlı kademeli reaktörün tasarımını yapacak bir programın "giriş parametreleri" şunlardır: Kademeli reaktörün çalışma frekansı, nominal akım değeri, toplam öz indüktans değeri, kademe değerleri (ör: \%50, $\% 75, \% 85, \% 100)$, kullanılacak tel türü ( $\mathrm{Al}$ or $\mathrm{Cu}$ ), her bir bobinde müsaade edilecek en büyük akım yoğunluğu, reaktör iç çap değeri, reaktör toplam paket sayısı, her bir paketteki bobin sayısı, bir paketi oluşturan bobinler arasına konacak yalıtım kağıdının kalınlığı, paketler arasına konulacak köpek kemiğini kalınlığı, tüm bobinlerin yalıtımlı ve yalıtımsız kesit çap1, (eğer tüketici arzu ediyorsa) kademeli reaktörün kısa devre akım değeri, (eğer arzu ediliyor ise) reaktör bobinlerinin en düşük ve en yüksek sıcaklık değeri, (eğer isteniyor ise) kademeli reaktörün kısa devre süresi. Hava nüveli çok katmanlı ve kademeli bir reaktörün tasarımını yapacak programın ürettiği "çıktı parametreleri" şunlardır: Kademeli reaktörün her bir kademesi için gerçek akım değerleri, her bir akımın açı değeri, her bir kademe için reaktör doğru akım (DA) direnç değerleri (hem $25^{\circ} \mathrm{C}$ hem de $75^{\circ} \mathrm{C}$ için), kademeli reaktörün reaktif güç değeri, kademeli reaktörün kalite faktörü, tüm paketler içinde yer alan bobinlerin ayrı ayrı sarım sayıları, tüm bobinlerin toplam tel uzunluğu, tüm reaktörün toplam aktif güç kaybı, reaktörün yüksekliği, reaktörün toplam iletken ağırlığı, reaktörün toplam ağırlığı, tüm kademelerdeki reaktör gerçek öz indüktans değeri. Şekil 1'de, yatay durumda, 4 kademeli, hava nüveli çok katmanlı kademeli bir reaktörün enine kesiti görülmektedir (reaktör 4 paket içermektedir ve her pakette 1 bobin mevcuttur). Şekil 1'de görülen kademeli reaktörde 4 paket ve her bir paket içinde yalnızca bir adet bobin (layer) bulunmaktadır. Şekil $2^{\prime}$ de, şalt sahasında çalışır durumda olan, 5 kademeli, hava



Şekil 1. Yatay pozisyonda 4 kademeli hava nüveli reaktör enine kesit (Cross section of an air core4 tapped reactor (horizontal position) 
nüveli çok katmanlı bir reaktörün resmi gösterilmiştir. Şekil 3'de ise, k. reaktör kademesinde, hava nüveli çok katmanlı kademeli bir reaktörün eşdeğer devre modeli gösterilmiştir. Şekil 3'de görülen eşdeğer devre modeli, n adet paket içeren ve her pakette $\mathrm{m}$ tane bobin bulunan bir reaktör için geçerlidir. Bu durumda, kademeli, çok katmanlı reaktördeki toplam bobin sayısı, m*n adettir. Eğer, k. kademe için, tüm reaktör bobinlerine Kirchhoff gerilim yasası uygulanır ise, Eş. 1'de görülen denklem sistemi elde edilir. Eş 1'de, w açısal frekansı, k. kademe durumu için; $\mathrm{L}_{\mathrm{ik}} \mathrm{i}$. bobin öz indüktansını, $R_{i k}$ i. bobin direncini, $I_{i k}$ i. bobin akımının fazörünü, $M_{(i j) k} i$. bobin ile j. bobin arasındaki ortak indüktansı, $\mathrm{V}_{\text {tapk }}$ reaktör gerilimini, $\mathrm{I}_{\text {tapk }}$ ise toplam reaktör akımını göstermektedir.



Şekil 2. Hava nüveli 4 kademeli reaktör [16]

(Air core tapped reactor with 4 taps)

$$
\begin{aligned}
& V_{\text {tap } k}=j w L_{1 k} I_{1 k}+j w M_{(1,2) k} I_{2 k}+\ldots . .+ \\
& j w M_{(1, j) k} I_{j k}+\ldots+j w M_{\left(1, m^{*} n\right) k} I_{\left(m^{*} n\right) k}+R_{1 k} I_{1 k} \\
& V_{\text {tap } k}=j w M_{(2,1) k} I_{1 k}+j w L_{2, k} I_{2 k}+\ldots \ldots+ \\
& j w M_{(2, j) k} I_{j k}+\ldots+j w M_{\left(2, m^{*} n\right) k} I_{\left(m^{*} n\right) k}+R_{2, k} I_{2 k} \\
& V_{\text {tap } k}=j w M_{(i, 1) k} I_{1 k}+j w M_{(i, 2) k} I_{2 k}+. .+ \\
& j w L_{i k} I_{i k}+. .+j w M_{(i, j) k} I_{j k}+\ldots+j w M_{\left(i, m^{*} n\right) k} I_{\left(m^{*} n\right) k}+R_{i k} I_{i k} \\
& V_{\text {tap } k}=j w M_{\left(m^{*} n, 1\right) k} I_{1 k}+j w M_{\left(m^{*} n, 2\right) k} I_{2 k}+\ldots+ \\
& j w L_{\left(m^{*} n\right) k} I_{\left(m^{*} n\right) k}+. .+j w M_{\left(m^{*} n j\right) k} I_{j k}+\ldots+ \\
& j w L_{\left(m^{*} n, m^{*} n\right) k} I_{\left(m^{*} n\right) k}+R_{\left(m^{*} n\right) k} I_{\left(m^{*} n\right) k}
\end{aligned}
$$

Eş. 1, matris formunda tekrar yazılır ise, Eş. 2'de verilen fazör denklemi elde edilir.

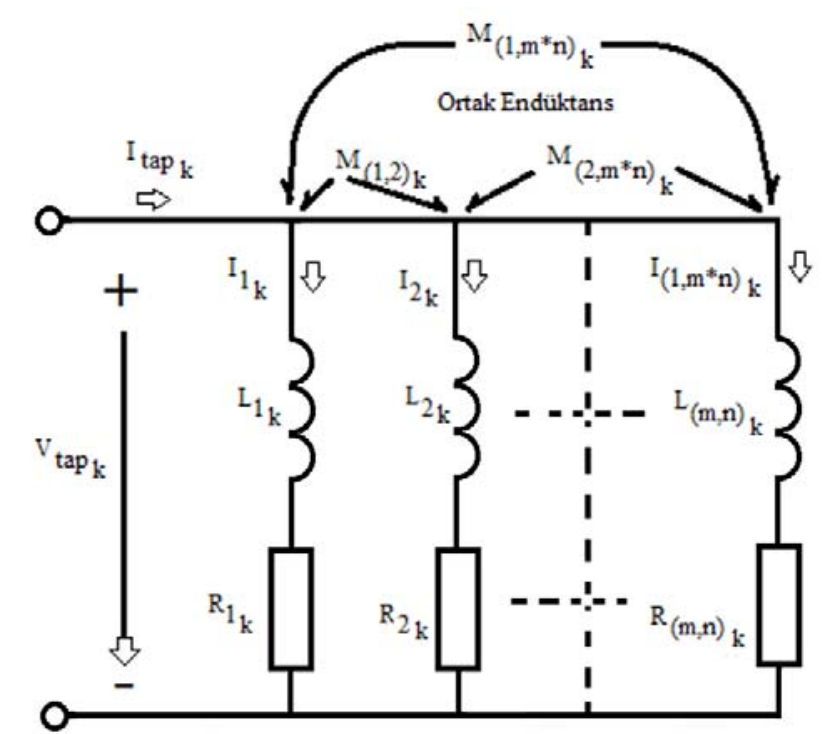

Şekil 3. k kademeli, hava nüveli çok katmanlı reaktörün devre modeli [14]

(A circuit model of air core multilayer reactor with tap $\mathrm{k}$ )

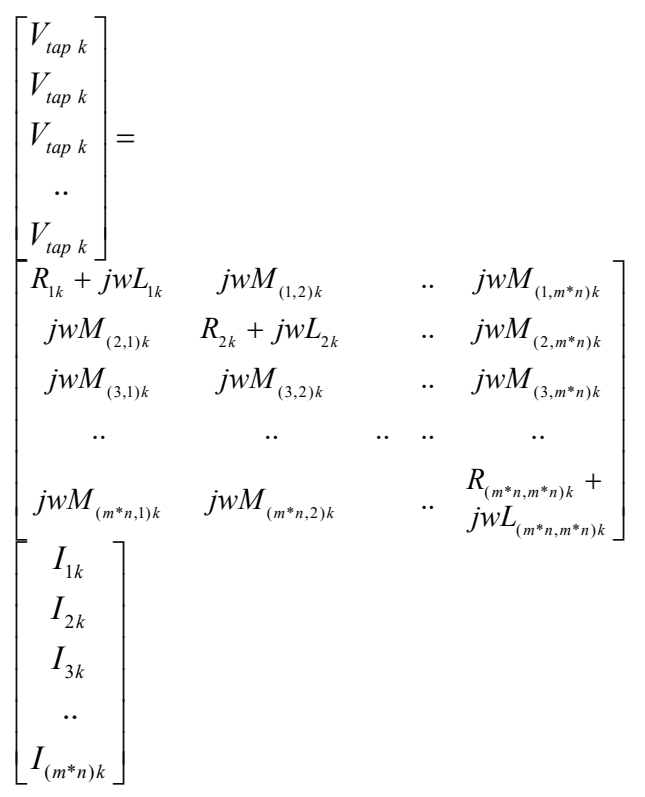

$\mathrm{L}_{\mathrm{ik}}$ Öz indüktans ve $\mathrm{M}_{(\mathrm{ij}) \mathrm{k}}$ ortak indüktans değerlerinin hesab1 bir sonraki bölümde açıklanacaktır. Reaktörün k. kademesi için tüm reaktör bobinlerine Kirchhoff akım yasası uygulanır ise, Eş. 3'de görülen fazör denklemi elde edilir:

$$
\mathrm{I}_{1 \mathrm{k}}+\mathrm{I}_{2 \mathrm{k}}+\ldots \ldots . .+\mathrm{I}_{(\mathrm{m} * \mathrm{n}) \mathrm{k}}=\mathrm{I}_{\text {tap } \mathrm{k}}
$$

\subsection{Hava Nüveli Kademeli Reaktörün Öz Indüktans Değerinin Hesaplanmast}

(Calculation of The Self Inductance of The Air Core Tappaed Reactor)

Kirchhoff formülü gibi [17], Eş. 4'de verilen Maxwell formülünde de, bitişik sarımlar arasındaki ortak indüktans değerlerinin hesabı için eliptik entegraller kullanılır. 
Tasarımın, n (tam sayı) sarımlı bir bobin için yapılması durumunda; $h$ bobin yüksekliğini, $r$ bobin yarıçapını, $\beta$ tel yarıçapını, c tel çapını, g(z) z modülü için eliptik integral değerini, $\mathrm{k}$ modülü için $\mathrm{K}$ birinci dereceden tam eliptik integrali, $\mathrm{E}$ ise ikinci dereceden tam eliptik entegral değerlerini gösterir. Yukarıda tanıtılan tüm parametreler kullanılarak, bobinin öz indüktans değeri Eş. 4 gibi hesaplanabilir [18]:

$$
\begin{aligned}
& \mathrm{L}=\mathrm{ng}(0)+2(\mathrm{n}-1) \mathrm{g}(\gamma)+2(\mathrm{n}-2) \mathrm{g}(2 \gamma)+\ldots . .+2 \mathrm{~g}((\mathrm{n}-1) \gamma) \\
& \mathrm{g}(\mathrm{z})=\mu_{\mathrm{o}} \frac{\mathrm{r}}{\mathrm{k}}\left[\left(2-\mathrm{k}^{2}\right) \mathrm{K}-2 \mathrm{E}\right] \\
& \mathrm{k}^{2}=\frac{4 \mathrm{r}^{2}}{\mathrm{~h}^{2}+\mathrm{z}^{2}} ; \mathrm{g}(0)=\mu_{\mathrm{o}} \mathrm{r}\left(\ln \frac{8 \mathrm{r}}{\beta}-\frac{7}{4}\right) ; \gamma=\frac{\mathrm{h}}{\mathrm{n}}
\end{aligned}
$$

Eş. 4 ve Eş. 5, farklı şekillerdeki bobinlere de uygulanabilir. Bunun için farklı tip bobinin, çeşitli dairesel bobin parçalarından oluştuğu kabulü yapılabilir. Russel [19], Eş. 4 ve Eş. 5'de, Eş. 6'da gösterilen;

$$
\mathrm{g}(0)=\mu_{\mathrm{o}} \mathrm{r}\left(2(\mathrm{~K}-\mathrm{E})+\frac{1}{4}\right) ; \mathrm{k}=\frac{\mathrm{r}-\beta}{\mathrm{r}}
$$

eliptik entegrallerini kullanarak, farklı tipteki bobinlerin, öz indüktans değerlerini hesaplamıştır. Snow formülleri [20], Lorenz [21] formüllerinin daha karmaşık bir halidir. Bu formüller, Maxwell [18] veya Kirchhoff [17] formüllerinin dairesel bobinlere uygulanmış şeklidir. $\mathrm{Bu}$ formüllerde toplama işlemi gerekmediğinden, daha hızlı sonuca ulaşmak mümkün olabilmektedir.

$$
\begin{aligned}
& \mathrm{p}=\frac{2 \mathrm{r}}{\mathrm{h}} ; \quad \theta=\tan ^{-1} \mathrm{p} ; \quad \mathrm{k}=\sin \theta ; \\
& \mathrm{k}^{\prime}=\cos \theta ; \quad \mathrm{z}=\frac{\pi \mathrm{nc}}{\mathrm{h}} ; \beta=0.5 \mathrm{c}
\end{aligned}
$$

Öz indüktans hesaplamalarında daha hızlı sonuca ulaşmak için, Eş. 6 ve Eş. 7 ifadeleri, Eş. 4'de yerlerine konulursa, öz indüktans için yeni formül Eş. 8'de gösterildiği gibi olacaktır.

$$
\begin{aligned}
& L=\frac{\mu_{o}}{4 \pi}\left\{\frac{8 n^{2} r \pi}{3}\left[\frac{K+\left(p^{2}-1\right) E}{k}-p^{2}\right]+\right. \\
& 2 \pi r\left[2 n(0.25-\ln z)+\frac{1}{3} \ln \left(\frac{2 \pi n r}{h}\right)-\frac{4}{\pi^{2}}\left(\frac{E}{k}-1\right)\left(1+\frac{z^{2}}{8}\right)-\right. \\
& \left.\left.\frac{2}{3}\left(\frac{K-E}{k}-\frac{k K}{2}\right)-\frac{k^{\prime}}{2 k}\left(1-\frac{k^{\prime} \theta}{k}\right)\right]+h\left(\ln \frac{1+k^{\prime}}{1-k^{\prime}}+k^{\prime} \ln 4\right)\right\}
\end{aligned}
$$

K ve E entegrallarinin açık formu Eş. 9'da gösterilmiştir.

$$
\begin{aligned}
& \mathrm{K}=\mathrm{F}(\mathrm{k}, \pi / 2)=\mathrm{F}(\mathrm{k})=\int_{0}^{\pi / 2} \frac{\mathrm{d} \varphi}{\sqrt{1-\mathrm{k}^{2} \sin ^{2} \varphi}} ; \\
& \mathrm{E}=\mathrm{E}(\mathrm{k}, \pi / 2)=\mathrm{E}(\mathrm{k})=\int_{0}^{\pi / 2} \sqrt{1-\mathrm{k}^{2} \sin ^{2} \varphi} \mathrm{d} \varphi
\end{aligned}
$$

\subsection{Hava Nüveli Kademeli Reaktörün Ortak Indüktans Değerinin Hesaplanması (The Calculation of The Mutual Inductances of The Air Core Tapped Reactor)}

İki solenoidin, düzgün levha şeklinde sarıldığı kabul edilirse, ikisi arasındaki ortak indüktans değeri, [22] referansında gösterildiği gibi, Eş. 10 yardımı ile hesaplanabilir. Eş. 10'da, $\mathrm{k}$. kademe değeri için, $\mathrm{b}_{1}$ birinci solenoidin tabanının referans alınan noktadan uzaklığını, $b_{2}$ ikinci solenoidin tabanının referans alınan noktadan uzaklığını, $\mathrm{h}_{1}$ birinci solenoid yüksekliğini, $\mathrm{h}_{2}$ ikinci solenoid yüksekliğini, $\mathrm{n}_{1}$ birinci solenoid sarım sayısını, $\mathrm{n}_{2}$ ikinci solenoid sarım sayısını göstermektedir. Eğer her iki solenodin tabanları referans alınan eksen ile çakışık ise $b_{1}=b_{2}=0$ alınmalıdır.

$M=\frac{2 \pi n_{1} n_{2}}{h_{1} h_{2}}\left\{\begin{array}{l}W\left(b_{2}-b_{1}+h_{2}\right)+W\left(b_{2}-b_{1}+h_{1}\right)- \\ W\left(b_{2}-b_{1}+h_{2}-h_{1}\right)-W\left(b_{2}-b_{1}\right)\end{array}\right\}$

$\mathrm{r}_{1}$ birinci solenoidin yarıçap1, $\mathrm{r}_{2}$ ise ikinci solenoidin yarıçap1 (reaktörün k. kademe değeri için) olmak üzere, Eş. 10'da görülen $\mathrm{W}(\mathrm{x})$ ifadesinin açık ifadesi Eş. 11'de verilmiştir:

$$
\mathrm{W}(\mathrm{x})=\mathrm{xW}^{\prime}(\mathrm{x})+\frac{8\left(\mathrm{r}_{1} \mathrm{r}_{2}\right)^{3 / 2}}{3 \mathrm{k}}\left[\mathrm{K}-\left(\frac{2}{\mathrm{k}^{2}}-1\right)(\mathrm{K}-\mathrm{E})\right]
$$

Eş. 11'de görülen $W^{\prime}(x)$ ifadesinin açık gösterimi ise Eş. 12'de verilmiştir:

$$
\begin{aligned}
& W^{\prime}(x)=\frac{2 x \sqrt{r_{1} r_{2}}}{k}(K-E) \pm \\
& \left|r_{1}^{2}-r_{2}^{2}\right|\left[K E\left(k^{\prime}, \theta\right)-\left((K-E) F\left(k^{\prime}, \theta\right)-\frac{\pi}{2}\right]\right.
\end{aligned}
$$

Eş. 11 ve Eş. 12'de görülen diğer parametrelerin karş1lıkları ise Eş. 18'de verilmiştir [23].

$$
\begin{aligned}
& \mathrm{k}=\sqrt{\frac{4 \mathrm{r}_{1} \mathrm{r}_{2}}{\mathrm{x}^{2}+\left(\mathrm{r}_{1}+\mathrm{r}_{2}\right)^{2}}} ; \\
& \mathrm{k}^{\prime}=\sqrt{1-\mathrm{k}^{2}} ; \theta=\sin ^{-1} \sqrt{\frac{1+\frac{\mathrm{x}^{2}}{\left(\mathrm{r}_{1}+\mathrm{r}_{2}\right)^{2}}}{1+\frac{\mathrm{x}^{2}}{\left(\mathrm{r}_{1}-\mathrm{r}_{2}\right)^{2}}}}
\end{aligned}
$$

Eş. 11'de, $\mathrm{x}$ değeri pozitif ise, işaret veya \pm içeren terim pozitif olacaktır. $r_{1}=r_{2}$ ise ve $x=0$ ise (bobinler birbirlerine dokunuyor ise), $\mathrm{k}=1$ olacaktır. $\mathrm{Bu}$ durumda $\mathrm{W}(\mathrm{x})$ ifadesi, bir limite doğru yaklaşacaktır. Eş. 10-13 ifadeleri, 3. dereceden tam eliptik entegraller kullanılarak Eş. 12, Eş. 14'de verilen biçimde de yazılabilir.

$$
W^{\prime}(x)=x\left\{z(K-E)+\frac{\left(r_{1}^{2}-r_{2}^{2}\right)}{z}[K-\Pi(k, c)]\right\}
$$


Eş. 14'de görülen parametrelerin karşılıkları Eş. 15'de gösterilmiştir.

$$
\mathrm{z}=\sqrt{\left(\mathrm{r}_{1}^{2}-\mathrm{r}_{2}^{2}\right)+\mathrm{x}^{2}} ; \mathrm{k}=2 \sqrt{\frac{\mathrm{r}_{1} \mathrm{r}_{2}}{\mathrm{z}^{2}}} ; \mathrm{c}=2 \sqrt{\frac{\mathrm{r}_{1} \mathrm{r}_{2}}{\left(\mathrm{r}_{1}+\mathrm{r}_{2}\right)^{2}}} ;
$$

Eş. 14, Eş. 16'da gösterildiği gibi, Eş. 14, Heuman'ın Lamda fonksiyonu olan ve $\Lambda_{\mathrm{o}}(\mathrm{k}, \theta)$ ile gösterilen ifade cinsinden de yazilabilir.

$$
\mathrm{W}^{\prime}(\mathrm{x})=\frac{2 \mathrm{x} \sqrt{\mathrm{r}_{1} \mathrm{r}_{2}}}{\mathrm{k}}(\mathrm{K}-\mathrm{E}) \pm \mid \mathrm{r}_{1}^{2}-\mathrm{r}_{2}^{2}\left[\frac{\pi}{2}\left[\Lambda_{\mathrm{o}}(\mathrm{k}, \theta)-1\right]\right]
$$

Eş. 16'da görülen parametrelerin karşıllkları, Eş. 17'de verilmiştir.

$$
\begin{aligned}
& k=\sqrt{\frac{4 r_{1} r_{2}}{x^{2}+\left(r_{1}+r_{2}\right)^{2}}} ; \\
& \theta=\sin ^{-1} \sqrt{\frac{1+\frac{\mathrm{x}^{2}}{\left(\mathrm{r}_{1}+\mathrm{r}_{2}\right)^{2}}}{1+\frac{\mathrm{x}^{2}}{\left(\mathrm{r}_{1}-\mathrm{r}_{2}\right)^{2}}}}
\end{aligned}
$$

\subsection{Minimum Kademe Değerinde Reaktörün Kısa Devre Testi}

(Short Circuit Test of The Reactor For Minimum Tap K)

$\mathrm{F}_{1}$ reaktörün başlangıç sıcaklık değeri $\left({ }^{\circ} \mathrm{C}\right), \mathrm{F}_{2}$ reaktörün son sıcaklığ $1\left({ }^{\circ} \mathrm{C}\right)$ ve $\mathrm{F}_{3}$ 'de reaktörün kısa devre süresi $(\mathrm{sn})$ ise, en küçük k kademe değeri için, kısa devre koşulları altında, bobin akımının akım yoğunluk değeri, alüminyum iletken için, ampirik formül olarak Eş. 18'de verilmiştir [20].

$$
F_{4}=\sqrt{\left(\frac{21800}{F_{3}}\right) \log \left(\frac{235+F_{2}}{235+F_{1}}\right)} \quad\left(\mathrm{A} / \mathrm{mm}^{2}\right)
$$

Eğer bobinde, iletken olarak bakır tel kullanılırsa, en küçük k kademe değeri için, Eş. 18 yerine Eş. 19 kullanılmalıdır $[20]$.

$$
F_{4}=\sqrt{\left(\frac{49804}{F_{3}}\right) \log \left(\frac{235+F_{2}}{235+F_{1}}\right)} \quad\left(\mathrm{A} / \mathrm{mm}^{2}\right)
$$

Eş. 18 ve Eş. 19'da verilen 21800 ve 49804 sabitlerinin birimleri $\left.\left(\mathrm{A}^{2} / \mathrm{mm}^{4}\right)\right)$ dir. Kısa devre hesaplamalarında, en küçük k kademe değeri için, reaktörün tüm bobin kesitleri toplamı, Eş. 20'de verilen kesit değerinden büyük olması gerekir. En küçük kademe değeri için, $\mathrm{F}_{5}$ kademeli reaktörün kısa devre akımını göstermek üzere, bobin tel kesit değeri Eş. 20 ifadesi ile hesaplanır.

$$
S=\frac{F_{5}}{F_{4}}\left(m m^{2}\right)
$$

\subsection{Reaktörün En Dıştaki Bobinine İlişkin Sarım Sayısının Hesaplanmasl \\ (Formulation of Number of Spirs of the Outer Layer)}

$\mathrm{L}_{1}$ en diş bobinin öz indüktans değeri (henry) olmak üzere, k. kademe değeri için, reaktörün en dıştaki bobinine ilişkin (N) sarım sayısı hesabı Eş. 21'de verilmiştir [24].

$$
\mathrm{N}=\left(\mathrm{L}_{1} 10^{6}\right)-\mathrm{A}_{1}+\mathrm{A}_{2}
$$

Yalıtılmış telin çapı d $(\mathrm{cm}), \mathrm{k}$. kademe için reaktörün iç çap $\mathrm{D}(\mathrm{cm})$ olmak üzere, Eş. 21'de görülen $\mathrm{A}_{1}$ ve $\mathrm{A}_{2}$ ifadelerinin açık yazılışları, Eş. 22 ve Eş. 23'de gösterilmiştir [24].

$$
\begin{aligned}
\mathrm{A}_{1}= & 0.002 \pi \mathrm{D}_{1} \mathrm{~N}^{2}\left(\log \left(1+\frac{0.5 \pi \mathrm{D}_{1}}{\mathrm{dN}}\right)\right) \\
A_{2}= & \frac{1}{2.3+\left(3.437 d N / D_{1}\right)+1.7636\left(d N / D_{1}\right)^{2}-} \\
& 0.47\left(\left(0.755+\left(d N / D_{1}\right)\right)^{1.44}\right.
\end{aligned}
$$

\subsection{Minimum Kademe Değerinde Kademeli Reaktörde Gerilim Dayanımı (Voltage Withstand Levels of An Air Core Tapped Reactor For Minimum Tap K)}

Hava nüveli çok katmanlı kademeli reaktörler için, yalıtım dayanımı açısından, iki temel ölçü bulunmaktadır. Temel yalıtım seviyesi (B.I.L) (diğer bir adlandırma ile yıldırım gerilimi dayanımı) ve güç frekansındaki gerilim dayanımı. Şönt reaktörler, üç fazlı sisteme, üçgen ya da yıldız olarak bağlanırlar. Bu durumda, bir adet kademeli reaktörün iki ucu arasına ya faz arası gerilimi ya da faz-toprak gerilimi gelecektir. Kademeli reaktörün en küçük kademe değerinde, iki ucu arasına uygulanacak gerilim değeri (üst gerilimden alt gerilim seviyesine doğru), reaktörün her spiri üzerinde kademeli olarak azalacaktır. Eğer, birbirini takip eden iki sarım arasındaki gerilim farkı, o noktadaki atlama geriliminden büyük değerde ise (bunun anlamı; reaktöre uygulanan gerilime göre o bobindeki seri bağlı sarım sayısı yetersiz (az) kalmaktadır), reaktörün o bölgesinde, yalıtım probleminden kaynaklanan kisa devre meydana gelmesi kaçınılmazdır. Genel olarak, hava nüveli çok katmanlı bir kademeli reaktörün en diş bobinden en içteki bobine kadar sarım sayısındaki değişim (eğer aynı çapta tel kesiti kullanılıyor ise), Şekil 4'de gösterildiği gibidir (en diştaki bobinde daha çok, içteki bobinlere doğru ise girdikçe azalır). Şekil 5'de ise, en küçük k kademe değerinde, reaktöre aynı gerilim değeri $\left(\mathrm{V}_{\text {tapk }}\right)$ uygulanmış, birbirini takip eden bobinlerin her bir sarıma düşen gerilim değişimi gösterilmiştir. Örneğin, en küçük k. kademe değerinde, m. bobin $\mathrm{N}$ sarımlı ise, birbirine seri bağlı iki sarım arasındaki gerilim farkı (düşümü) $\mathrm{V}_{\text {tapk }} / \mathrm{N}$ olacaktır. Ĕger (m-1). Bobin $\mathrm{K}$ adet sarıma sahip ise, bu bobindeki seri bağlı iki sarım arasındaki gerilim farkı, en küçük k kademe değeri için, $V_{\text {tapk }}$ / K olacaktır. Bu burumda, birbirine komşu olan iki bobinde, aynı seviyelerdeki sarımlar arasındaki gerilim farkı önem kazanmaktadır. Şekil 5'de görülen birbirlerine komşu olan A ve B sarımları arasındaki gerilim farkının değeri, en küçük k kademe değeri için, Eş. 24'de verilmiştir. 


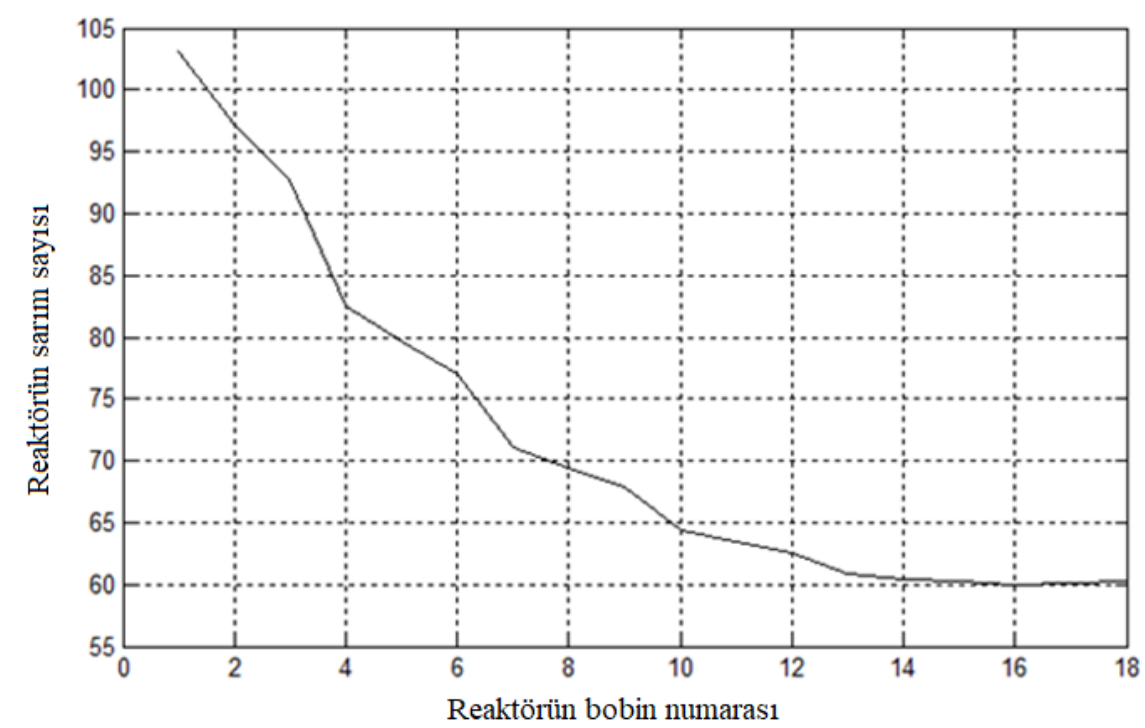

Şekil 4. Genel olarak, içten dışa doğru reaktör bobin sayısının reaktör bobin sarım sayısına göre değişimi (In general the change in the number of reactor coils from the inside to the outside according to the number of turns of the reactor coils)

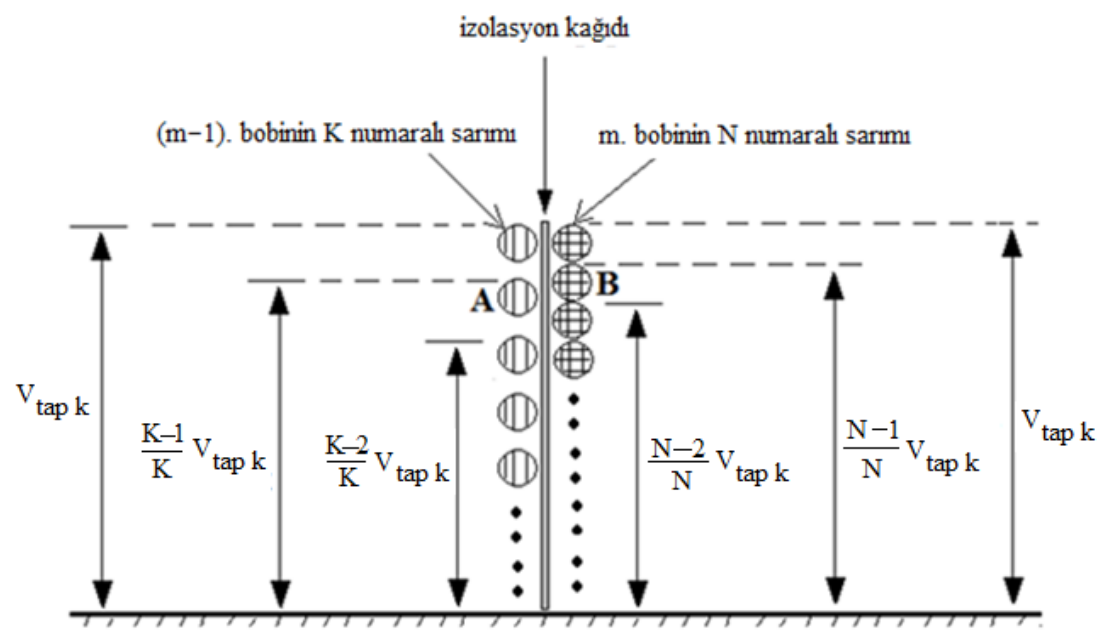

Şekil 5. k kademe değeri için, iki komşu bobinin sarımları arasındaki gerilim seviyeleri (The voltage level on spirs of two neighbour the layers for tap $\mathrm{k}$ )

$$
\mathrm{V}_{\mathrm{A}-\mathrm{B}}=\left(\frac{\mathrm{K}-1}{\mathrm{~K}}-\frac{\mathrm{N}-1}{\mathrm{~N}}\right) * \mathrm{~V}_{\mathrm{tapk}}
$$

Eğer Eş. 24'de bulunan gerilim değeri, bu noktadaki atlama gerilim değerinden daha büyük ise, en küçük kademe değeri için, A ve B telleri arasında kısa devre meydana gelecektir. Hava nüveli çok katmanlı kademeli reaktör hesaplamalarında, reaktör çap değeri ile reaktör yüksekliğinin ters orantılı olduğu görülecektir. Tüm algoritma sona erdikten sonra, optimum reaktör yüksekliği ve optimum reaktör çapı bulunur. Bu iki değer için Şekil 5'de verilen A ve B noktalarının atlama gerilim değerinin üstünde olup olmayacağı kontrol edilmelidir.

\subsection{Hava Nüveli, Çok Katmanl, Kademeli Bir Reaktörün Optimum Tasarımını Yapan Algoritma (Optimim Design Algorithm of Air Core Multilayer Tapped Reactor)}

Şekil 6'da verilen algoritma, $\mathrm{k}=4$ kademeli, hava nüveli çok katmanlı bir reaktöre uygulanmıştır. Reaktörün nominal akım değeri $385 \mathrm{~A}, 50 \mathrm{~Hz}$ dir. $\mathrm{k}=1$ için $\mathrm{L}=7,5 \mathrm{mH}, \mathrm{k}=2$ için $\mathrm{L}=12,75 \mathrm{mH}, \mathrm{k}=3$ için $\mathrm{L}=12,75 \mathrm{mH}$ ve $\mathrm{k}=4$ için ise $\mathrm{L}=15 \mathrm{mH}$ dir.

1- Şebeke frekansını $(\mathrm{Hz})$, reaktörün nominal akım değerini (A) ve kademeli reaktöre ilişkin en büyük öz indüktans değerini $(\mathrm{mH})$ giriniz. 


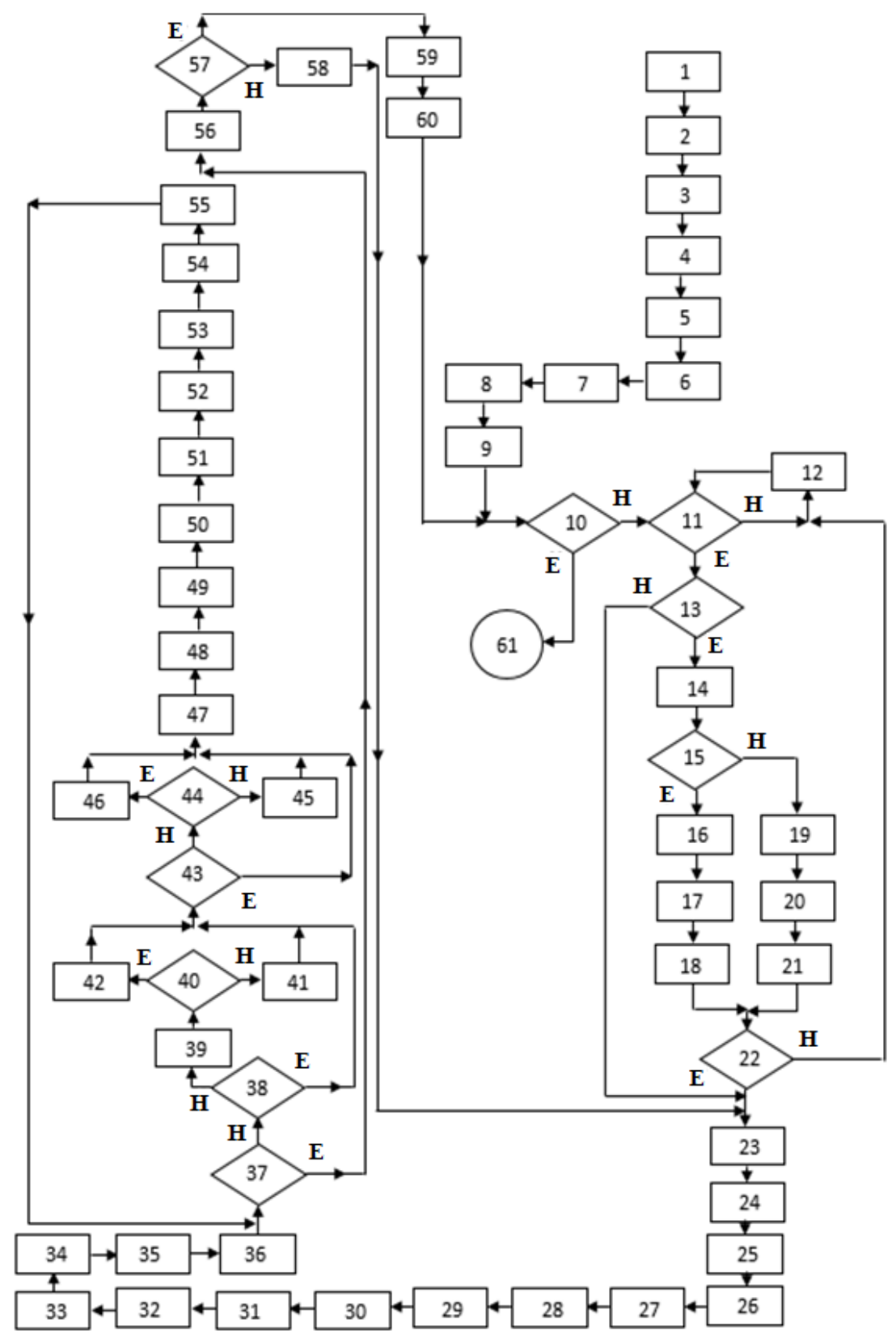

Şekil 6. Hava nüveli, çok katmanlı, kademeli bir reaktörün optimum tasarım algoritması (Flowchart of the optimum design of an air core multilayer tapped reactor)

2- Kademeli reaktörün her bir farklı kademe değerlerine karşı gelen öz indüktans değerlerini $(\mathrm{mH})$ küçükten büyük değere doğru giriniz.

3- Bobinlerde kullanılacak telin malzeme türünü ( $\mathrm{Al}$ or $\mathrm{Cu})$ ve telin akım yoğunluğunu $(\mathrm{A} / \mathrm{mm} 2)$ giriniz.

4- Kademeli reaktöre ilişkin, önerilen algoritmanın kullanacağı reaktör iç çap başlangıç değerini ve iç çap bitiş değerini $(\mathrm{cm})$, küçük değeri önce, büyük değeri sonra olacak şekilde giriniz.

5- Kademeli reaktöre ilişkin paket sayısını ve bir paket içinde kullanılacak paralel bağlı bobin sayısını giriniz.

6- Başlangıç öz indüktans değeri olarak, kademeli reaktörün en düşük öz indüktans değerini (mH) kullanınız.
7- Bir paket içinde yer alan bobinlerin arasına konulacak olan yalıtkan kâğıt kalınlığını (mm) ve iki paket arasına yerleştirilecek olan köpek kemiği kalınlığını $(\mathrm{cm})$ giriniz. 8- En dış bobinden başlayarak, içe doğru, her bir bobinde kullanılacak telin yalıtımlı ve yalıtımsız çap değerini (mm) sirası ile giriniz.

9- İlk iterasyon değerini 1 alarak, algoritmaya ilişkin, müsaade edilecek en büyük iterasyon sayı değerini giriniz. 10-Kademeli reaktörün şu andaki (mevcut döngüdeki) iç çap değeri, 4. adımda belirlenen iç çap son değerinden $(\mathrm{cm})$ büyük mü?

11-Kademeli reaktörü oluşturan tüm paralel bobinlerin toplam akım değeri (A), 1. adımda girilen, reaktörün nominal akımına (A) dayanabilecek mi? 
12-İlgili bobin için (eski değerinden daha büyük olan) yeni bir tel çap değeri $(\mathrm{mm})$ belirleyiniz.

13-Kademeli reaktör siparişinde reaktörün dayanması gereken kısa devre akım şartı mevcut mu?

14-Kademeli reaktörün (en düşük kademedeki) kısa devre akım değerini (A) giriniz.

15-Reaktörün bobinleri için tel olarak bakır tel $(\mathrm{Cu}) \mathrm{mi}$ kullanılacak?

16-Bobinlerin dayanması gereken en büyük tel sıcaklık değerini $\left({ }^{\circ} \mathrm{C}\right)$ giriniz.

17-Kademeli reaktörün (en düşük kademedeki) kısa devre akım süresini (sn) giriniz.

18-Eş. 19 yardımı ile kademeli reaktörün kısa devre akımına ilişkin akım yoğunluğunu $(\mathrm{A} / \mathrm{mm} 2)$ hesaplayınız.

19-Bobinlere ilişkin başlangıç ve son sıcaklık değerini $\left({ }^{\circ} \mathrm{C}\right)$ giriniz.

20-Kademeli reaktöre ilişkin kısa devre süresini (sn) giriniz. 21-Eş. 18'i kullanarak, kademeli reaktörün kısa devre akım yoğunluğunu $(\mathrm{A} / \mathrm{mm} 2)$ hesapla.

22-Eş. 20 kullanıldığında, kademeli reaktörün tüm bobinleri kısa devre akımına dayanmakta mıdır?

23-Mevcut kademe değeri için, kademeli reaktörün akımına ilişkin, kabul edilebilir alt ve üst sınır değerlerini (A) giriniz. 24-Kademeli reaktörün en diştaki bobinine ilişkin öz indüktans değerini $(\mathrm{mH})$, kademeli reaktörün, bu kademedeki öz indüktans değerinden, 1,25 kat büyük $(\mathrm{mH})$ olacak şekilde belirleyiniz.

25-Eş. 16-18'yi kullanarak, kademeli reaktörün (bu kademedeki) en dıştaki bobinine ilişkin sarım sayısını hesaplayınız.

26-En dış bobinin sarım sayısını esas alarak, içeriye doğru bobin sarım sayılarını, kendisinin dışındaki bobinin sarım sayısının \%20 si kadar düşük alacak şekilde belirleyiniz.

27-Kademeli reaktörün bu kademedeki empedansı (ohm) ve kademeli reaktör akım (A) değerini kullanarak, kademeli reaktör uçları arasında elde edilen gerilim düşümünü (V) hesaplayını.

28-Kademeli reaktörün bu kademedeki yüksekliğini $(\mathrm{cm})$, en dış bobin yüksekliği $(\mathrm{cm})$ yardımı ile yaklaşık olarak belirleyiniz.

29-Mevcut kademesindeki tüm bobin çaplarını (cm) belirleyiniz.

30-Tüm bobinlere ilişkin ortalama çap $(\mathrm{cm})$, sarım sayıları ve yükseklikleri $(\mathrm{cm})$, Eş. 8,9 'da kullanarak, bobinlere ilişsin indüktans $(\mathrm{mH})$ değerlerini ayrı ayrı hesaplayınız.

31-Tüm bobinlere ilişkin ortalama çap $(\mathrm{cm})$, sarım sayıları ve yükseklikleri (cm), Eş. 10 - 17'de kullanarak, tüm bobinler arasındaki ortak indüktans $(\mathrm{mH})$ değerlerini ayrı ayrı hesaplayınız.

32-Tüm bobinlerin DA direnç değerini (ohm) hem $25^{\circ} \mathrm{C}$ hem de $75^{\circ} \mathrm{C}$ için hesaplayınız.

33-Eş. 2'yi kullanarak, kademeli reaktörün bu kademesine ilişkin empedans matrisini (ohm) hesaplayınız.

34-Eş. 2'de verilen gerilim değeri ve empedans matrisini kullanarak, reaktörün mevcut kademe değerindeki tüm bobinlere ilişskin akım değerlerini (A) bulunuz.

35-Eş. 3'ü kullanarak, paralel bağlı tüm bobin akım değerlerini toplayıp, kademeli reaktörün bu kademedeki akım değerini (A) bulunuz.
36-Kademeli reaktörün bu kademedeki indüktans değerini $(\mathrm{mH})$, reaktör akımı $(\mathrm{A})$, reaktör gerilimi $(\mathrm{V})$ ve frekans $(\mathrm{Hz})$ yardımı ile bulunuz.

37-Kademeli reaktörün bu kademesindeki akım değeri (A) kabul edilebilir limit değerler arasında mi? Ve her bir bobinin akım değeri (A) kendi limit değerinin arasında mı? Ve iterasyon sayısı kabul edilebilir değerin altında kalıyor $\mathrm{mu}$ ?

38-Tüm bobin akımları (A) kendi limit değerleri arasında kaliyor mu?

39-Akım üst limit değerini aşan bobinleri tespit et. Akım değeri (A), limit değerler arasında kalan bobinlerin sarım sayılarında değişiklik yapma.

40-Bobin akım değeri (A) kendi limit değerinin altında kaldı $\mathrm{mi}$ ?

41-Akım değeri limit değerin üzerine çıkan bobinlere (iterasyon sayısına bağlı olarak değişen) bir katsayı yardımı ile sarım ilave et.

42-Akım değeri limit değerin altına inen bobinlerden (iterasyon sayısına bağlı olarak değişen) bir katsayı yardımı ile sarim azalt.

43-Kademeli reaktörün bu kademesindeki akım değeri (A), reaktörün alt ve üst sınır değerleri arasında kalıyor mu?

44-Kademeli reaktörün bu kademesindeki akımı (A), reaktör akım alt limitinin altında $\mathrm{m}$ ?

45-Kademeli reaktörün bu kademesindeki alt akım limitini (A), iterasyona bağlı olarak değişen bir katsayı yardımı ile azalt.

46-Kademeli reaktörün bu kademesindeki alt akım limitini (A), iterasyona bağlı olarak değişen bir katsayı yardımı ile artir.

47-Kademeli reaktörün bu kademedeki yüksekliğinin $(\mathrm{cm})$ bobin sarım sayıları yardımı ile tekrar hesapla.

48-Mevcut kademe değerinde, son hesaplanan sarım sayıları, bobin çapları $(\mathrm{cm})$ ve bobin yüksekliklerini $(\mathrm{cm})$ kullanarak, tüm bobinlerin öz indüktans $(\mathrm{mH})$ değerlerini Eş. $(8,9)$ yardımı ile tekrar hesaplayınız.

49-Mevcut kademe değerinde, tüm bobinlerin son hesaplanan sarım sayılarını, bobin çaplarını $(\mathrm{cm})$, bobin yükseklikleri $(\mathrm{cm})$ ve son hesaplanan öz indüktans $(\mathrm{mH})$ değerlerini kullanarak, Eş. 10 - 17 eşitliği yardımı ile tüm bobinler arasındaki karşılıklı ortak indüktans değerlerini $(\mathrm{mH})$ hesaplayınız.

50-Mevcut kademe değerinde, tüm bobinlerin kesit ve tel uzunluklarını kullanarak, doğru akım (DA) direnç değerlerini (ohm) hesaplayınız.

51-Eş. 2'yi kullanarak, kademeli reaktörün bu kademesine ilişkin empedans matrisini oluştur.

52-Eş. 2 denklemini kullanarak, kademeli reaktörün mevcut kademe değerindeki reaktör empedans matrisi ve reaktör gerilim değeri (V) yardımı ile tüm bobin akımlarını (A) hesaplayınız.

53-Eş. 3 yardımı ile tüm bobin akımlarını toplayarak, kademeli reaktörün bu kademedeki akım değerini (A) hesaplayinız.

54-Kademeli reaktörün bu kademedeki akım (A), gerilim ve frekans $(\mathrm{Hz})$ değerlerini kullanarak, reaktör öz indüktans $(\mathrm{mH})$ değerini hesaplayınız. 




a)

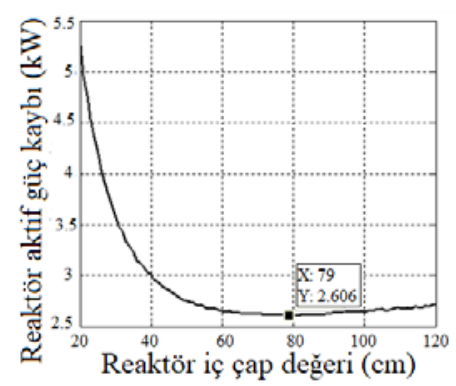

b)

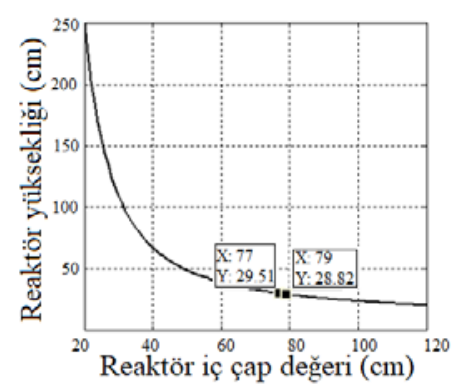

c)

Şekil 7. Kademeli çok katmanlı reaktörün iç çap değerinin a) reaktör ağırlığına göre değişimi b) aktif güç kaybına göre değişimi c) reaktör yüksekliğine göre değişimi (The variation of the multilayer reactor internal diameter to a) weight of wire of the reactor b) DC active power loss of the reactor c) height of the reactor)

Tablo 1. HILLKAR ${ }^{\circledR}$ firmasınca üretilen reaktörlerin $L$ değerlerine ilişkin sipariş, üretim, tolerans ve fark değerleri (The $\mathrm{L}$ values of the reactors produced by $\mathrm{HILKAR}^{\circledR}$ order, production, tolerance and difference values)

\begin{tabular}{llllll}
\hline $\begin{array}{l}\text { Reaktör Akımı } \\
(\mathrm{A})\end{array}$ & $\begin{array}{l}\text { L tolerans } \\
\text { değeri }(\%)\end{array}$ & $\begin{array}{l}\text { Sipariş L } \\
(\mathrm{mH})\end{array}$ & $\begin{array}{l}\text { Üretilen L } \\
(\mathrm{mH})\end{array}$ & $\begin{array}{l}\text { Fark L } \\
(\%)\end{array}$ & $\begin{array}{l}\text { Reaktör S1caklık } \\
\text { Değeri }\left({ }^{\circ} \mathrm{C}\right)\end{array}$ \\
\hline 150 & \pm 5 & 4,9 & 5,1367 & $+4,8$ & 45 \\
100 & \pm 5 & 92,84 & 92,98 & $+0,15$ & 60 \\
125 & \pm 5 & 30,95 & 31,07 & $+0,3872$ & 55 \\
125 & \pm 5 & 26,2 & 26,63 & $+1,64$ & 55 \\
100 & \pm 5 & 13,26 & 13,60 & $+2,59$ & 50 \\
1200 & \pm 5 & 1 & 0,97 & $-0,3$ & 65 \\
675 & \pm 5 & 3 & 2,95 & $-1,67$ & 62 \\
1250 & $-0 /+20$ & 0,45 & 0,466 & $+3,5$ & 71 \\
2000 & $-0 /+20$ & 0,3 & 0,313 & $+4,3$ & 55 \\
30 & $-0 /+20$ & 100 e-3 & $105 \mathrm{e}-3$ & +5 & 20 \\
154 & \pm 5 & 9,13 & 8,82 & $-3,39$ & 35 \\
\hline
\end{tabular}

55- İterasyon sayısını artır.

56-Mevcut kademeye ilişkin bobin akımları, bobin sarım sayıları, bobin yüksekliklerini yazdırınız.

57-Kademeli reaktörün tüm kademe işlemleri sona erdi mi? 58-Kademe sayısını 1 artır.

59-Kademeli reaktör akım değerini (A), reaktör akım açısını (derece), reaktörün hem $25^{\circ} \mathrm{C}$ hem de $75^{\circ} \mathrm{C}$ deki doğru akım (DA) direnç değerini, reaktörün reaktif güç değerini ( $\mathrm{kVAr}$ ), kademeli reaktörün kalite faktörünü, tüm bobinlerin sarım sayılarını, tüm bobinlerin tel uzunluklarını (m), kademeli reaktörün toplam güç kaybını $(\mathrm{kW})$, reaktörün toplam ağırlığını (kg), reaktörün yüksekliğini $(\mathrm{cm})$, kademeli reaktörün toplam tel ağırlığını $(\mathrm{kg})$, kademeli reaktörün öz indüktans değerini $(\mathrm{mH})$ hesaplayınız.

60-Reaktörün iç çap değerini $1 \mathrm{~cm}$ arttırınız.

61-DUR

\section{3. ÖNERILEN ALGORITTMAYA AİT ÖRNEK TASARIM ÇALIŞMASI \\ (SAMPLE DESIGN STUDY WITH RECOMMENDED ALGORITHM)}

Reaktörde $9 \mathrm{~mm}$ çapında alüminyum tel kullanılmıştır. Reaktörde 6 paket ve her pakette ise birer bobin (layer) mevcuttur. Önerilen algoritma, kademeli reaktör iç çap değerini $60 \mathrm{~cm}$ 'den başlayarak 1'er cm artışa 288 cm'ye kadar artırmaktadır. Algoritma 1405 komut satırı ile yazılmıştır.
Programın çalıştırılması sona erdiğinde, kullanıcının elinde, algoritmada belirtilen tasarım çıktı değerlerine ilave olarak, Şekil 7'de gösterilen 3 farklı eğriyi çizdirecek bilgi de bulunmaktadır. Şekil 7'de, her 3 eğri üzerinde optimum (kritik) değerler işaretlenmiştir. İlk eğri; reaktör iç çap değerinin reaktör tel ağırlığına göre değişimi, ikinci eğri; reaktör iç çap değerinin reaktör yüksekliğine göre değişimi ve üçüncü eğri ise, reaktör iç çap değerinin reaktör aktif güç (DA) kaybına göre değişimini vermektedir. Eğer, reaktör siparişini veren firma için ağırlık en önemli kıstas ise, Şekil 7.a'da görülen eğrinin en küçük değeri, tasarım için gerekli iç çap değerini verecektir $\left(D_{\text {opt }}=211 \mathrm{~cm}, \mathrm{G}_{\mathrm{opt}}=621,1 \mathrm{~kg}\right)$. Eğer reaktörün en küçük doğru akım aktif güç kaybı siparişi veren firma için en önemli kıstas ise, Şekil 7.c'de görülen eğrinin en küçük değeri, tasarım için gerekli iç çap değerini verecektir $\left(D_{\text {opt }}=221 \mathrm{~cm}, P_{\text {opt }}=7,3 \mathrm{~kW}\right)$. Şekil 7.b'de ise optimum (ağırlık) iç çap değeri için, reaktörün optimum yükseklik değeri işaretlenmiştir $\left(D_{\text {opt }}=221 \mathrm{~cm}, H_{\text {opt }}=80 \mathrm{~cm}\right)$. Algoritmanın ürettiği diğer tasarım çıktıları burada verilmemiştir.

\section{SONUÇLAR (CONCLUSIONS)}

Şekil 6'da verilen algoritma, piyasadan gelebilecek reaktör siparişlerinin gerçek sipariş değerlerine göre çalışmakta, algoritma sona erdiğinde elde edilen tasarım sonuçları kullanılarak, kademeli reaktör üretimi rahatlıkla 
yapılabilmektedir. Önerilen algoritma, literatürde görülen birçok yöntemden farklı olarak, karmaşık katsayıların hesaplanmasına gerek olmayan bir içeriğe sahiptir. Önerilen algoritma, silindirik bobinlerde, değişik iletken kalınlık ve tiplerinde de çalışabilmektedir. Bu özelliği ile de, üreticinin deposunda bulunan (değişik kalınlıktaki) iletkenlerin, reaktör imalatında kullanılması da mümkündür. Önerilen algoritma, aynı zamanda, müşteri tarafindan talep edilen reaktör kısa devre gücü, kısa devre süresi, reaktörün kabul edilebilir öz indüktans tolerans aralığı, reaktörün kabul edilebilir nominal akım tolerans aralığ kalite faktörü tolerans aralığı gibi parametrelere de dikkat ederek tasarım yapabilecek bir alt yapıya da sahiptir.

Şekil 6'da verilen algoritmanın üzerine bina edilen yazılım programı kullanılarak, General Electric (USA) tarafindan siparişi verilen; 4,9 $\mathrm{mH}(150 \mathrm{~A}), 13,26 \mathrm{mH}(100 \mathrm{~A}), 26,2$ $\mathrm{mH}(125 \mathrm{~A}), 30,95 \mathrm{mH}(125 \mathrm{~A}), 92,84 \mathrm{mH}(100 \mathrm{~A})$ değerindeki çok katmanlı hava nüveli reaktörler HILKAR ${ }^{\circledR}$ (Adapazarı), firmasınca imal edilmiş, standart testlerden geçirilmiş, Amerika'ya yollanmış ve sorunsuz olarak çalışmaya devam etmektedir. Tablo 1'de yukarıda bahsedilen reaktörlerin sipariş edilen değerleri ile gerçekleşen L (öz indüktans) değerleri verilmiştir.

\section{KAYNAKLAR (REFERENCES)}

1. Saribulut L., Teke A., Latran M.B., Multi-functional static synchronous compensator for distribution systems, Journal of the Faculty of Engineering and Architecture of Gazi University, 31 (3), 727-736, 2016.

2. Akdemir M., Yıldırım S., Genç N., Design and simulation of active direct current filter for high voltage direct current transmission systems, Journal of the Faculty of Engineering and Architecture of Gazi University, 31 (4), 1073-1083, 2017.

3. Deniz E., Aydoğmuş Ö., Design and implementation of two-phase matrix converter, Journal of the Faculty of Engineering and Architecture of Gazi University, 32 (1), 9-20, 2017.

4. Özdemir E., Özdemir Ş., ,Erhan K., Aktaş A., Opportunities and challenges for energy storage applications in smart grid, Journal of the Faculty of Engineering and Architecture of Gazi University, 32 (2), 499-506, 2017.

5. Liu Z.G., Wang J.H., Wang W.P., Development and Application of Dry Type Air Core Reactor Design Software, Electric Machines and Control, 6 (7), 103106, 2003.

6. Xiuke Y., Guiping Y., Magnetic Field Research and Circulating Current Calculation of Power Reactor with Air Core, J. Transformer, 47 (6), 1-4, 2010.

7. Sippola M., Sepponen R.E., Accurate Prediction of High Frequency Power Transformer Losses and Temperature Rise, IEEE Trans. on Power. Electronics, 17 (5), 835847, 2002.

8. Zhigang L., Jianhua W.J., Yingsan G., Calculation of Temperature Field of Dry Type Air Core Damping
Reactor Based on Coupled Method, Journal of Xi an Jiaotong University, 37 (6), 59-63, 2003.

9. Enohnyaket M., Ekman J., PEEC Models for Air Core Reactors Modeling Skin and Proximity Effects, Power Electronics Specialists Conference, PESC IEEE, 30343038, 2007.

10. Zhigang L., Yingsan G., Wang J., Degui C., Anbo W., Design and Analysis of New Type Air Core Reactor Based on Coupled Fluid Thermal Field Calculation, Transactions of China Electrotechnical Society. 18 (6), 59-63, 2003.

11. Dongbai Z., Yingxin M., A Assigning Method for Air Core Power Reactor, Harbin Institute of Electrical Technology Journal 1, 54-59, 1996.

12. Yu Z., Wang S., Optimum design of dry-type air-core reactor based on coupled multi-physics of reconstructed finite element model, Transaction of China Electrotechnical Society, 30 (20), 71-78, 2015.

13. Xia T.,Yan Y., Optimum Design of Dry Type Air Core Current Limited Reactor, Electric Machines and Control, 1, 51-53, 1998.

14. Yuan Zheng Z., Feng C., Kang B., Xikui M., Optimum Design of Dry Type Air Core Reactor Based on the Additional Constraints Balance and Hybrid Genetic Algorithm, Inter. J. of App. Electromagnetics and Mechanics, 33, 279-284, 2010.

15. Jian L., Zhenhai Z., Longnv L., Guoli L., Manhua J., Calculation and Design of Dry Type Air Core Reactor, Energy and Power Engineering, 5, 1101-1104, 2013.

16. http://www.trenchgroup.com/en/Downloads/CoilProducts

17. Kirchhoff, G.1864. Zur Theorie der Entladung Einer Leydner Flasche, Annalen der Physik, 71, 551-566.

18. Maxwell J.C, A Treatise on Electricity and Magnetism, Dover Publications Inc, New York, 1954.

19. Alexander R., The Magnetic Field and Inductance Coefficients of Circular, Cylindrical, and Helical Currents, Proc. Phys. Soc. London, 20 (1), 476-506, 1906.

20. Chester S., Formulas for Computing Capacitance and Inductance, National Bureau of Standards Circular, U.S. Govt. Print. Off., 544, 1954.

21. Lorenz L., Ueber die Fortpflanzung der Flectricität, Annalen der Physik, 7, 161-193. 1879.

22. Viriamu J., On the Calculation of the Coefficient of Mutual Induction of A Circle and A Coaxial Helix, and of the Electromagnetic Force Between a Helical Current and A Uniform Coaxial Circular Cylindrical Current Sheet, Phil. Trans. of the Roy. Soc., 63,192-205, 1898.

23. Babic S. and Akyel C., Improvement in Calculation of the Self and Mutual Inductance of Thin-Wall Solenoids and Disk Coils, IEEE Transactions on Magnetics 36 (4), 1970-1975, 2000.

24. Andersen O.W., Optimum Design of Electrical Machines. (Doktora tezi). Chalmers University of Technology, Göteborg,1969. 